\title{
A Study of the Possibility of Obtaining Deposited Coatings based on Intermetallic Titanium and Aluminum Compounds using the Chemical Vapor Transport Method
}

\author{
ANNA I. GUSEVA, ARKADY N. SILENKO \\ National Research Nuclear University MEPhI (Moscow Engineering Physics Institute), \\ Kashirskoe shosse 31, Moscow, 115409 \\ RUSSIA
}

\begin{abstract}
Theoretical and experimental investigations of processes of titanium-aluminum coating formation on refractory wire substrates by the Chemical Vapor Transport Reactions (CVT) method were carried out. Modelling of CVT was based on the thermodynamic analysis of an equilibrium iodide system implying the presence of one of titanium aluminides in the condensed phase, titanium and aluminum iodides in the gas phase, as well as atomic and molecular iodine. The fact that the volatility and stability of various metals are strongly interrelated was considered as a working hypothesis, which made it possible to obtain a number of alloys with the simultaneous decomposition of metal iodides constituting an alloy. Experiments on the deposition of titanium-aluminum coatings were conducted in a quasi-closed reactor, which allowed us to obtain deposited coatings on long-length refractory substrates.
\end{abstract}

Keywords: - Chemical Vapor Transport Reactions (CVT) method, titanium alloys, $\mathrm{Ti}_{3} \mathrm{Al}$ and $\mathrm{TiAl}$ intermetallic compounds

Received: March 28, 2021. Revised: September 11, 2021. Accepted: September 22, 2021. Published: October 1, 2021.

\section{Introduction}

Titanium alloys are materials that feature the highest specific strength; they demonstrate good processing properties and high corrosion resistance. The mechanical properties of titanium are characterized by a good combination of strength and plasticity.

Titanium-aluminum alloys are materials of the highest technological and industrial importance. Aluminum is a widespread, affordable, and low-cost metal. The introduction of aluminum into commercial titanium, even in small amounts (up to $13 \%$ ), makes it possible to sharply increase the heat resistance of an alloy while reducing its density and cost. This alloy is an excellent structural material. The addition of $3-8 \%$ aluminum increases the temperature of transformation of $\alpha$-titanium into $\beta$ titanium. Aluminum is the only alloying stabilizer of $\alpha$-titanium that increases its strength while keeping the plasticity and toughness properties of the titanium alloy constant; it also increases the heat resistance, the creep resistance, and the elastic modulus of this alloy [1].

TiAl intermetallic compounds are widely used in various fields as lightweight construction materials. With their low density, they have the advantageous properties of a high melting point, high modulus of elasticity, good antioxidant capacity, high specific strength and sufficient creep resistance at elevated temperatures $[2,3]$.

The $\mathrm{Ti}-\mathrm{Al}$ phase diagram is characterized by the presence of wide regions of solid solutions based on $\alpha$ - and $\beta$-Ti and the $\operatorname{TiAl}(\gamma)$ compound.

Later studies confirmed the existence of only two compounds - $\mathrm{Ti}_{3} \mathrm{Al}$ and $\mathrm{TiAl}_{2}$ - in addition to TiAl and $\mathrm{TiAl}_{3}$ that have already been known.

Among the intermediate phases formed in the $\mathrm{Ti}-\mathrm{Al}$ system, aluminides $\mathrm{Ti}_{3} \mathrm{Al}$ and $\mathrm{TiAl}$ are materials of the greatest practical interest. $\mathrm{The}^{\mathrm{T}} \mathrm{i}_{3} \mathrm{Al}$ intermetallic compound (the $\alpha_{2}$-phase) is a superstructure based on the $\alpha$-phase, in which titanium and aluminum atoms are arranged in an orderly manner. The $\mathrm{Ti}_{3} \mathrm{Al}$ intermetallic compound has a hexagonal close-packed structure with a unit cell whose period $a \alpha$ is twice the period $a \alpha$ of the $\alpha$ phase and period $c$ is the same as that of the $a$-phase $\left(a \alpha_{2}=0.577 \mathrm{~nm}\right.$ and $\left.c \alpha_{2}=0.462 \mathrm{~nm}\right)$ [11].

The plasticity of the $\mathrm{Ti}_{3} \mathrm{Al}$ intermetallic compound is negligible, which can be attributed to the peculiarities of its dislocation structure and the properties of dislocations. At room temperature, plastic deformation of the $\mathrm{Ti}_{3} \mathrm{Al}$ intermetallic compound is mainly performed by sliding of paired superdislocations with the Burgers vector $b=a=1 / 3$ 
<1120>. Plastic deformation of $\mathrm{Ti}_{3} \mathrm{Al}$ at room temperature is limited, since dislocations $a=1 / 3$ $<1120>$ are able to slide only along the $\{1010\}$ planes, and the rest of the dislocations are hardly mobile due to blocking. As a result, the number of independent planes of sliding turns out to be less than five, which does not ensure the continuity of the metal during deformation according to the Mises criterion. An unstable shear occurs in local volumes in the course of deformation, which leads to the accumulation of dislocations and the initiation of microcracks [11].

The mechanical properties of the $\mathrm{Ti}_{3} \mathrm{Al}$ intermetallic compound at room temperature strongly depend on the impurity content, the microstructure type and parameters, and the micrograin size and shape. Therefore, the mechanical properties of the $\mathrm{Ti}_{3} \mathrm{Al}$ intermetallic compound vary within wide limits: TS $=220-600 \mathrm{MPa}$ and $\delta=0-0.5 \%$. The elastic moduli are less dependent on the above factors, and their values are: $E=140 \mathrm{GPa}$ and $G=$ $52.5 \mathrm{GPa}$. The density of the $\mathrm{Ti}_{3} \mathrm{Al}$ aluminide is 4.20 $\mathrm{g} / \mathrm{cm}^{3}$.

As the temperature rises, the ultimate tensile strength of brittle low-strength intermetallic compound increases to about $700^{\circ} \mathrm{C}$ and then decreases. The ultimate tensile strength of a higher quality intermetallic compound does not experience anomalous temperature dependence. A fracture is brittle up to $600^{\circ} \mathrm{C}$, so that the fracture occurs before the yield point is reached. The mobility of dislocations with Burgers vectors $1 / 3<1120\rangle$ and $1 / 6<1126>$ increases and transverse sliding and creep of dislocations begin to develop at temperatures above $650^{\circ} \mathrm{C}$, which causes the plasticity of the intermetallic compound to increase.

The creation of a fine-grained structure by applying thermomechanical treatment or powder metallurgy methods leads to a significant increase in the plasticity. The relative elongation of the finegrain $\mathrm{Ti}_{3} \mathrm{Al}$ intermetallic compound reaches $3.2 \%$ in the area of brittle fracture (at $400^{\circ} \mathrm{C}$ ) and increases from 15 to $45 \%$ upon transition to ductile fracture $\left(600-650^{\circ} \mathrm{C}\right)$. The $\mathrm{Ti}_{3} \mathrm{Al}$ intermetallic compound with such a structure exhibits signs of superplasticity at a temperature of $1000^{\circ} \mathrm{C}$ and a low strain rate $(\sigma=$ $120 \% ; T=0.46$ ) [11].

The chemical vapor transport reactions (CVT) method [4-6] is one of the most effective methods for obtaining pure substances and coatings for various purposes for a number of branches of modern technology.
The essence of the of chemical vapor transport reactions method is in the fact that a certain substance $\mathrm{A}$ in a liquid or solid state interacts with gaseous substance $\mathrm{B}$ in a reversible reaction with the production of gaseous products, which decompose with the release of substance $\mathrm{A}$ in solid or liquid phase when the equilibrium conditions change after transfer to another part of the system.

The presence of a concentration gradient, along with the reversibility of the heterogeneous reaction, is a necessary condition for the transfer. A concentration gradient may occur due to a temperature difference or when the ratio of gaseous substances changes.

Substantial purification of metals from substitutional and interstitial impurities is a specific feature of transport reactions. Cleaning (refining) occurs during transfer for the following reasons:

(1) impurities do not interact with a transporting agent;

(2) impurities form nonvolatile compounds with the transporting agent;

(3) the resulting volatile impurity compounds are stable under the conditions of deposition of the refined substance;

(4) the impurity itself is volatile, and it sublimates from the sediment.

The iodide decomposition process is mainly used to obtain high-purity metals. However, the volatility and stability of iodides of various metals are strongly interrelated, which makes it possible to obtain a number of alloys with the simultaneous decomposition of metal iodides that make up the alloy. This fact is true not only for iodide, but also for other halide systems.

The following factors are indicated as necessary conditions for obtaining alloys from the gas phase using the CVT method:

(1) elimination of the conditions for obtaining a single-crystal metal;

(2) the relative volatility of iodides;

(3) the relative stability of iodides;

(4) the relative volatility of metals;

(5) the thermodynamic activity of the second components in the alloy.

In the presence of a continuous series of solid solutions, even metals that do not deposit from iodides in a free state (aluminum) can be deposited in the form of alloys.

The applicability of this method for obtaining certain substances, as well as the possibility of forming coatings with a complex composition, can 
be judged from the results of a thermodynamic analysis of the gas-phase composition. The analysis of the gas-phase composition makes it possible to determine the main transport reactions occurring in the volume, as well as to estimate the temperature parameters necessary for the transfer of the initial components with the subsequent deposition of a coating with a given composition.

\section{Methods}

A thermodynamic analysis of the titanium-aluminum- iodine system was carried out in order to investigate the possibility of obtaining intermetallic titanium and aluminum compounds in the condensed phase by crystallization of their iodides in the gas phase.

The main objective of the calculation was to determine the parameters of a possible process of obtaining gas-phase coatings based on intermetallic compounds: $\mathrm{Ti}_{3} \mathrm{Al}$ and $\mathrm{TiAl}$. For this purpose calculations of the equilibrium gas-phase composition over the $\mathrm{Ti}_{3} \mathrm{Al}$ and $\mathrm{TiAl}$ compounds were performed, taking into account the thermodynamic parameters of chemical compounds in a condensed phase.

Thus, a system of independent equations for the reactor volume is as follows:

$$
\begin{aligned}
& 3\left(\mathrm{TiI}_{2}\right)+(\mathrm{AlI}) \leftrightarrow\left[\mathrm{Ti}_{3} \mathrm{Al}\right]+7(\mathrm{I}) \\
& \left(\mathrm{AlI}_{2}\right) \leftrightarrow(\mathrm{AlI})+(\mathrm{I}) \\
& \left(\mathrm{AlI}_{3}\right) \leftrightarrow\left(\mathrm{AlI}_{2}\right)+(\mathrm{I}) \\
& \left(\mathrm{TiI}_{4}\right) \leftrightarrow\left(\mathrm{TiI}_{2}\right)+2(\mathrm{I}) \\
& 2(\mathrm{I}) \leftrightarrow\left(\mathrm{I}_{2}\right) .
\end{aligned}
$$

All known iodides of titanium and aluminum, except $\mathrm{TiI}_{3}$ and $\mathrm{Al}_{2} \mathrm{I}_{6}$, were taken into account in this system compiled for the $\mathrm{Ti}_{3} \mathrm{Al}$ compound, since the results of the analysis of the titanium-iodine and aluminum-iodine systems indicate that the decomposition of these iodides occurs in the lowtemperature region (up to $400^{\circ} \mathrm{C}$ ).

A system of equations was constructed for reactions (1) based on the law of mass action that expresses the partial pressure of the iodides via the partial pressure of iodine:

$$
\begin{aligned}
& 3 \ln P_{\mathrm{Til} 2}+\ln P_{\mathrm{AlI}}-7 \ln P_{\mathrm{I}}=-20.58+90065 / T ; \\
& \ln P_{\mathrm{AII}}+\ln P_{\mathrm{I}}-\ln P_{\mathrm{AlI2}}=11.48-27925 / T-0.06 \ln T ; \\
& \ln P_{\mathrm{AlI} 2}+\ln P_{\mathrm{I}}-\ln P_{\mathrm{AlI} 3}=19.47-30185 / T+0.49 \ln T ; \\
& \ln P_{\mathrm{Ti} 2}+2 \ln P_{\mathrm{I}}-\ln P_{\mathrm{Til} 4}=31.31-52512 / T+0.16 \ln T ; \\
& \ln P_{\mathrm{I} 2}-2 \ln P_{\mathrm{I}}=-8.39-17985 / T-0.55 \ln T,
\end{aligned}
$$

where $T(\mathrm{~K})$ is the temperature, and

$P_{i}$ (atm) is the partial pressure of the $i$ th component.

When considering the quality of the intermetallic compound TiAl in the condensed phase, the first equation of the system (1) has the form:

$$
\left(\mathrm{TiI}_{2}\right)+(\mathrm{AlI}) \leftrightarrow[\mathrm{TiAl}]+3(\mathrm{I}),
$$

and the corresponding coupled equation of system (2) is as follows:

$$
\begin{aligned}
& 3 \ln P_{\mathrm{Ti} 2}+\ln P_{\mathrm{AlI}}-7 \ln P_{\mathrm{I}}=6.19+ \\
& 288831 / T-1.4 \ln T .
\end{aligned}
$$

Providing that there is no condensation of iodides and assuming the given ratio of titanium and aluminum atoms in the condensed phase, we can use the material balance equation:

$$
\left(P_{\mathrm{Til} 2}+P_{\mathrm{Til} 4}\right) /\left(P_{\mathrm{AlI}}+P_{\mathrm{AlI} 2}+P_{\mathrm{AlI} 3}\right)=3 .
$$

For the system (2)-(5), it is necessary to consider the implementation of the Dalton's law:

$$
P_{\Sigma}=P_{\mathrm{Til} 2}+P_{\mathrm{Ti} 14}+P_{\mathrm{AlI}}+P_{\mathrm{All} 2}+P_{\mathrm{All} 3} .
$$

The gas phase composition was calculated for a total pressure of $102 \mathrm{~Pa}$, which corresponded approximately to the heating temperature of $40^{\circ} \mathrm{C}$ for the iodine evaporator. The range $T=(400-1800)^{\circ} \mathrm{C}$ is chosen as the temperature range. The results of calculations for a condensed alloy based on $\mathrm{Ti}_{3} \mathrm{Al}$ compound are shown in Fig. 1.

Based on the results of the analysis, we can draw a conclusion that, when this model of description of CVT processes is used, the main transporting compounds in the gas phase are aluminum iodide and titanium diiodide in the temperature range of 900$1550^{\circ} \mathrm{C}$ and atomic iodine at temperatures above $1700^{\circ} \mathrm{C}$. The reactions of formation and decomposition of titanium diiodide and aluminum iodide are the main reactions determining the process of $\mathrm{Ti}_{3} \mathrm{Al}$ transfer. Moreover, the decomposition of these iodides should occur at temperatures not lower than $1550^{\circ} \mathrm{C}$. If the condensed phase is represented by $\mathrm{TiAl}$, the dissociation temperature of titanium diiodide and aluminum iodide increases up to 1750 $1800^{\circ} \mathrm{C}$. 


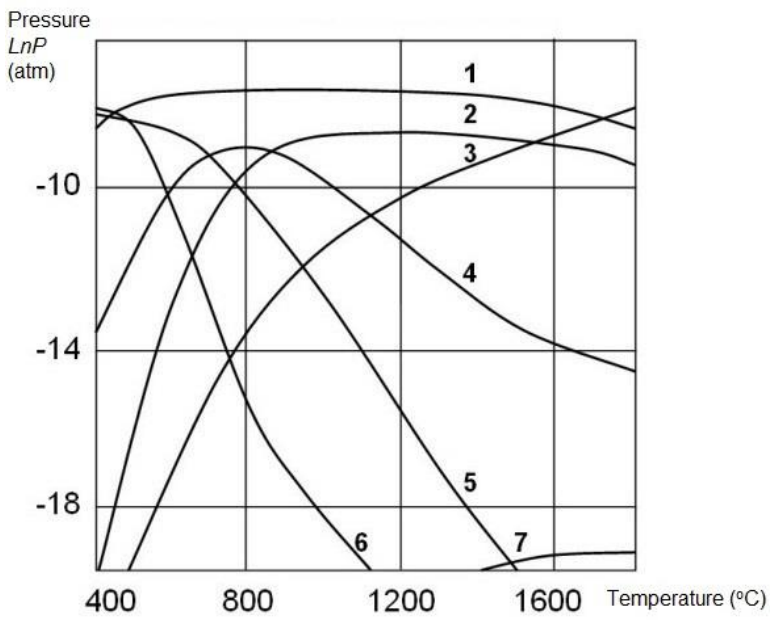

Fig. 1: The equilibrium composition of the gas phase in the titanium-aluminum-iodine system, provided that there is intermetallic compound $\mathrm{Ti}_{3} \mathrm{Al} ; P_{\Sigma}=102$ $\mathrm{Pa}\left(10^{-3} \mathrm{~atm}\right)$ in the condensed phase; $1-\mathrm{TiI}_{2} ; 2-$ AlI; $3-\mathrm{I} ; 4-\mathrm{AlI}_{2} ; 5-\mathrm{AlI}_{3} ; 6-\mathrm{TiI}_{4} ;$ and $7-\mathrm{I}_{2}$.

Experiments on the deposition of $\mathrm{Ti}_{3} \mathrm{Al}$ and $\mathrm{TiAl}$ coatings were carried out using quasi-closed laboratory apparatus. Devices of this type allow the use of a moving wire as a substrate, which provides the opportunity to exercise operational control over the coating deposition process [9].

The required technological parameters of the CVT process were set up based on the results of the thermodynamic analysis of the titanium-aluminum-iodine system. These parameters included the synthesis and dissociation temperatures of volatile iodides and the total pressure in the system.

The raw material, preliminarily melted in an arc furnace, was placed in the raw area of the reactor. The growth rate of coatings at different temperature parameters of the CVT process was determined by the increase in the wire diameter for a fixed time (in a static mode or in a dynamic (on the moving wire) mode of deposition).

\section{Results}

Thus, the thermodynamic analysis of the titanium-aluminum-iodine system carried out in accordance with the considered model demonstrates the possibility of obtaining titanium-aluminum deposition in the condensed phase by transferring alloys based on intermetallic compounds $\mathrm{Ti}_{3} \mathrm{Al}$ and $\mathrm{TiAl}$ in iodine systems.

The resulting data are in agreement with the results of the experiments. It should be noted that the calculated temperature of synthesis $\left(900^{\circ} \mathrm{C}\right)$ and decomposition $\left(1550-1750^{\circ} \mathrm{C}\right)$ of iodides was higher by $100-200^{\circ} \mathrm{C}$ than the experimental values. This fact can be explained by the presence of errors in determining the thermodynamic functions.

The study of the appearance of the sediments has made it possible to conclude that all the samples obtained were distinguished by the high continuity and the significant degree of surface roughness. The microstructure of samples with $\mathrm{Ti}-\mathrm{Al}$ coatings was characterized by the presence of a fine-crystalline sublayer and a columnar structure of the coating.

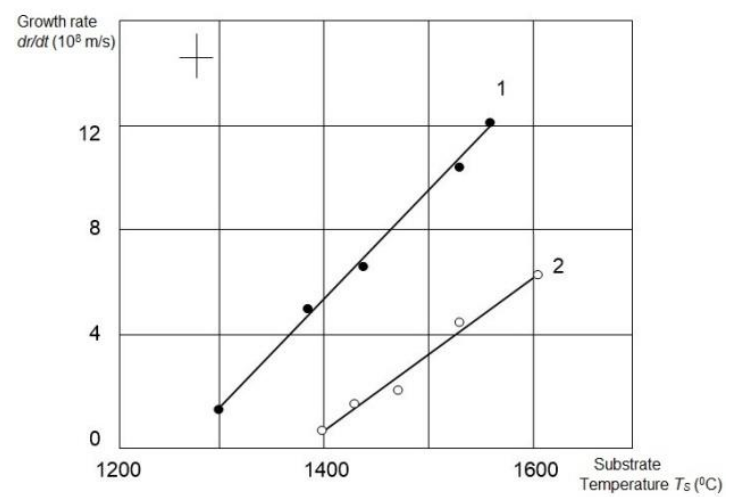

Fig. 2: The dependence of the growth rate of the titanium-aluminum coatings on the filament temperature: $T_{\text {sublimator }}=40^{\circ} \mathrm{C}, T_{\text {raw }}=900^{\circ} \mathrm{C} ; 1-$ raw material of an alloy based on $\mathrm{Ti}_{3} \mathrm{Al} ; 2$ - raw materials of an alloy based on TiAl.
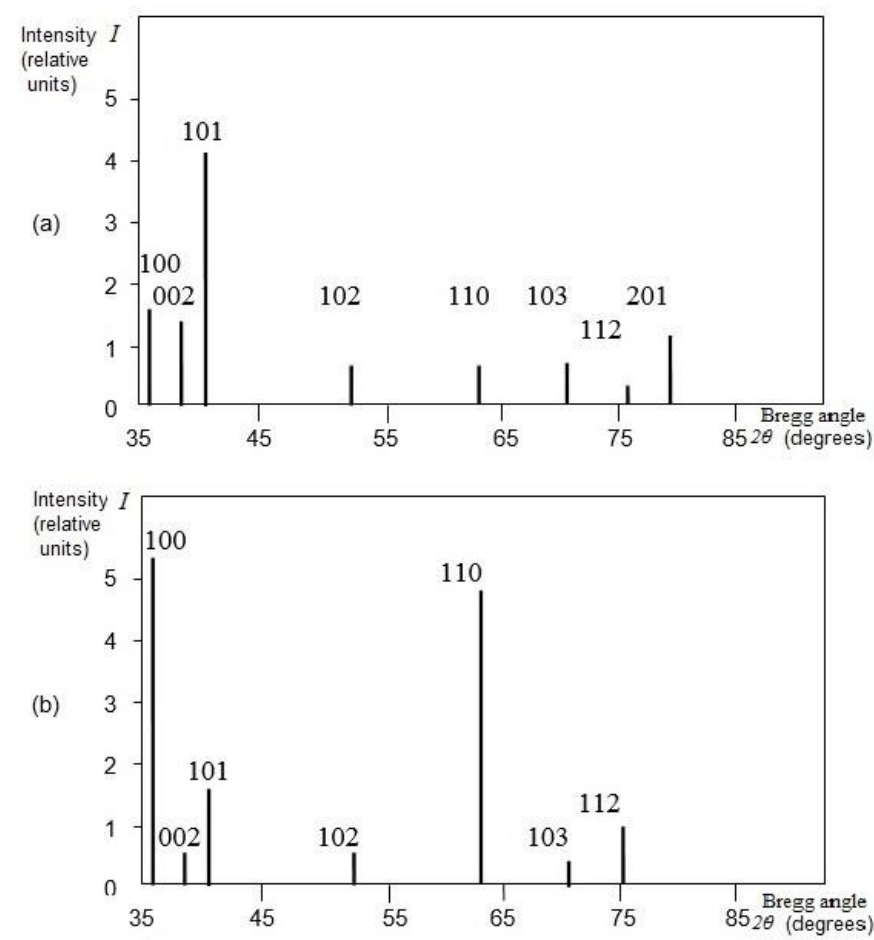

Fig. 3: The distribution of the intensities of $x$-ray peaks vs. the values of angle 20: (a) the raw alloy 
based on $\mathrm{Ti}_{3} \mathrm{Al}$ and (b) the coating obtained by transfer of the alloy based on $\mathrm{Ti}_{3} \mathrm{Al}$.

An increase in the deposition during the transfer of the alloy based on $\mathrm{Ti}_{3} \mathrm{Al}$ occurred at substrate temperatures of $1300-1600^{\circ} \mathrm{C}$. The dependence of the growth rate on the substrate temperature had a linear character (Fig. 2).

The increase in the temperature of the raw material from 700 to $900^{\circ} \mathrm{C}$ also led to the intensification of the coating-formation process. The relationship for the transfer of the alloy based on TiAl had a similar character. However, the dissociation temperature range was shifted towards higher temperatures $\left(1400-1700^{\circ} \mathrm{C}\right)$. The growth rates of the coatings were lower compared to the results obtained for the alloy based on $\mathrm{Ti}_{3} \mathrm{Al}$.

\section{DISCUSSION}

Samples of the initial alloys and the resulting coatings were subjected to $x$-ray structural and phase analysis. Fig. 3 shows the intensity distributions of $x-$ ray peaks versus the angle $2 \theta$ for the raw alloy based on $\mathrm{Ti}_{3} \mathrm{Al}$ and for the sample with a coating deposited during transfer of this alloy. These results indicate the presence of a single-phase structure (solid solution of aluminum in $\alpha$-titanium) in both raw materials and coatings.

This fact indicates that there was no ordering of the titanium-aluminum alloys with the release of the $\alpha_{2}$ structure of the $\mathrm{Mg}_{3} \mathrm{Cd}$ type under conditions of deposition of a raw alloy and deposition during the transfer of this alloy due to the short duration of these processes.

The coating is characterized by a significant increase in the intensities of the (100) and (110) lines. Therefore, we can draw a conclusion about the presence of a texture in the resulting titanium-aluminum coatings. The displacement of the deposit lines relative to the lines of the raw alloy also indicated that the aluminum concentrations in the raw materials and in the coating were different.

The presence of the disordered structure of the solid solution of aluminum in titanium both in the deposit and raw-material alloy based on $\mathrm{Ti}_{3} \mathrm{Al}$ allowed us to estimate the compositions of the raw alloys and deposits from the results of x-ray diffraction and literature data [10].

Table I shows the dependence of the lattice parameters $a$ and $c$ of $\alpha$-titanium on the aluminum concentration. Calculated values of the angle $2 \theta$ for the centers of gravity of lines (102), (110), (103), (200) are presented for the raw-material alloy based on $\mathrm{Ti}_{3} \mathrm{Al}$ and for one of the samples. The titanium and aluminum concentrations determined in this way were, respectively, 76 at. $\%$ and 24 at. $\%$ for the raw material and 82 at. \% and 18 at. \% for the coating.

The results obtained indicate the presence of significant quantities of carbon and oxygen in the surface layers of alloys. As one moved deeper into the material, a sharp decrease in the concentration of impurity elements was observed. This was caused by refinement of the deposit in the CVT process $[7,8]$. On the other hand, the surface layers of the resulting coating demonstrated a decrease in the aluminum content, which could be attributed to a change in the ratio of concentrations of $\mathrm{Ti}$ and $\mathrm{Al}$ upon their transfer to the gas phase in the CVT process.

The estimation of titanium and aluminum concentrations in the coatings obtained at different temperatures of the evaporator, raw materials, and substrate was carried out using $\mathrm{x}$-ray microanalysis. The results are shown in Table II. Based on these results, we can draw a conclusion about the weak influence of the temperature parameters on the composition of deposits.

Table 1. Results of the $\mathrm{x}$-ray analysis of the raw alloy and the deposit

\begin{tabular}{|c|c|c|c|c|}
\hline \multirow{2}{*}{ The sample } & \multirow{2}{*}{$\begin{array}{l}\text { Indexes of } \\
\text { the lines }\end{array}$} & \multirow{2}{*}{$\begin{array}{c}\text { Value of } \\
2 \theta \text {, degrees }\end{array}$} & \multicolumn{2}{|c|}{ Lattice parameters, $n m$} \\
\hline & & & $a \pm \Delta a$ & $c \pm \Delta c$ \\
\hline \multirow{4}{*}{$\begin{array}{l}\text { Raw alloy based } \\
\text { on } \mathrm{Ti}_{3} \mathrm{Al}\end{array}$} & 102 & 53.68 & \multirow{4}{*}{$0.2900 \pm 0.0003$} & \multirow{4}{*}{$0.4655 \pm 0.0001$} \\
\hline & 110 & 64.17 & & \\
\hline & 103 & 71.47 & & \\
\hline & 200 & 75.77 & & \\
\hline \multirow{4}{*}{$\begin{array}{l}\text { Cover Ti-Al; } \\
\mathrm{T}_{\text {sublimator }}=40^{\circ} \mathrm{C}, \\
\mathrm{T}_{\text {raw }}=700{ }^{\circ} \mathrm{C}, \\
\mathrm{T}_{\text {substrate }}=1500^{\circ} \mathrm{C}\end{array}$} & 102 & 53.64 & \multirow{4}{*}{$0.2909 \pm 0.0003$} & \multirow{4}{*}{$0.4659 \pm 0.0001$} \\
\hline & 110 & 64.06 & & \\
\hline & 103 & 71.38 & & \\
\hline & 200 & 73.77 & & \\
\hline
\end{tabular}



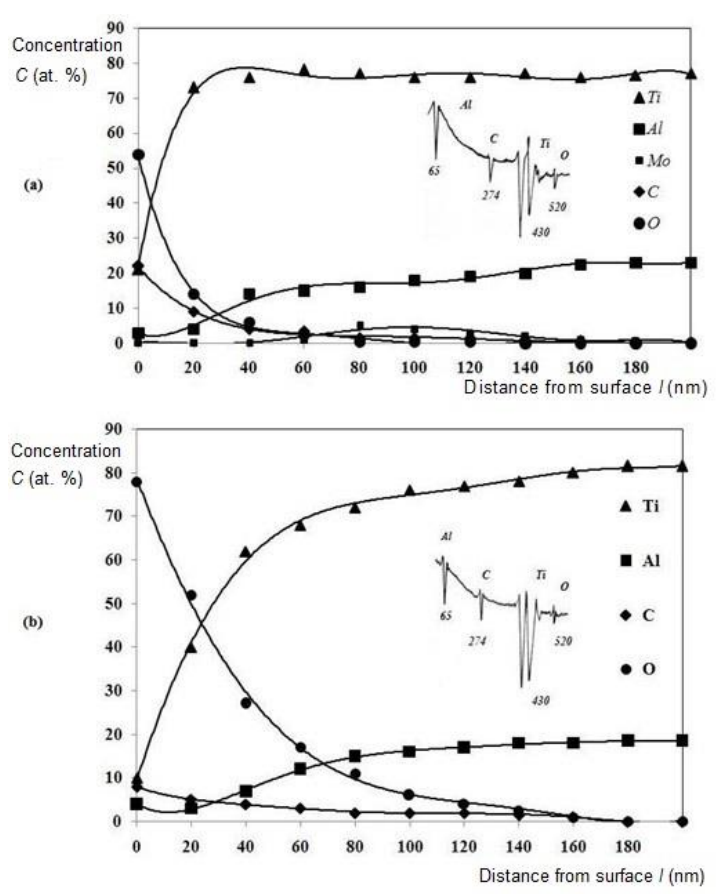

Fig. 4: The atomic concentration of elements in the surface layers of titanium-aluminum alloys: (a) the raw alloy based on $\mathrm{Ti}_{3} \mathrm{Al}$ and (b) the coating obtained by transfer of the alloy, $T_{\text {sublimator }}=40^{\circ} \mathrm{C}$, $T_{\text {raw }}=900^{\circ} \mathrm{C}$, and $T_{\text {wire }}=1400^{\circ} \mathrm{C}$.

The surface layers of the raw material and the deposited alloys were examined using auger electron spectroscopy. Fig. 4 shows the depth distributions of titanium, aluminum, and some impurities in the surface layers of the raw material on the basis of $\mathrm{Ti}_{3} \mathrm{Al}$ (Fig. 4a) and the alloy coating obtained on the W-Re wire (Fig. 4b).

Table 2. The atomic concentration of the metals in the alloy coatings based on $\mathrm{Ti}_{3} \mathrm{Al}$ and $\mathrm{TiAl}$ obtained at different temperature settings of the CVT process

\begin{tabular}{|c|c|c|c|c|}
\hline \multirow{2}{*}{$\begin{array}{c}\text { Raw } \\
\text { materials' } \\
\text { composition }\end{array}$} & \multirow{2}{*}{$\begin{array}{c}\text { Raw material } \\
\text { temperature, } \\
{ }^{o} \mathrm{C}\end{array}$} & \multirow{2}{*}{$\begin{array}{c}\text { Substrate } \\
\text { temperature, } \\
{ }^{\circ} \mathrm{C}\end{array}$} & \multicolumn{2}{|c|}{$\begin{array}{c}\text { Atomic } \\
\text { concentration, } \%\end{array}$} \\
\hline & & & $T i$ & $A l$ \\
\hline \multirow{6}{*}{$\begin{array}{l}\text { Alloy based on } \\
\mathrm{Ti}_{3} \mathrm{Al}\end{array}$} & 700 & 1420 & 83.9 & 16.1 \\
\hline & 800 & 1420 & 82.5 & 17.5 \\
\hline & 900 & 1420 & 82.9 & 17.1 \\
\hline & 900 & 1550 & 83.5 & 16.5 \\
\hline & 900 & 1380 & 83.7 & 16.3 \\
\hline & 900 & 1350 & 81.5 & 18.4 \\
\hline \multirow{5}{*}{$\begin{array}{l}\text { Alloy based on } \\
\text { TiAl }\end{array}$} & 700 & 1500 & 75.5 & 24.5 \\
\hline & 800 & 1500 & 75.2 & 24.8 \\
\hline & 900 & 1500 & 74.8 & 25.2 \\
\hline & 900 & 1400 & 74.5 & 25.5 \\
\hline & 900 & 1300 & 75.1 & 24.9 \\
\hline
\end{tabular}

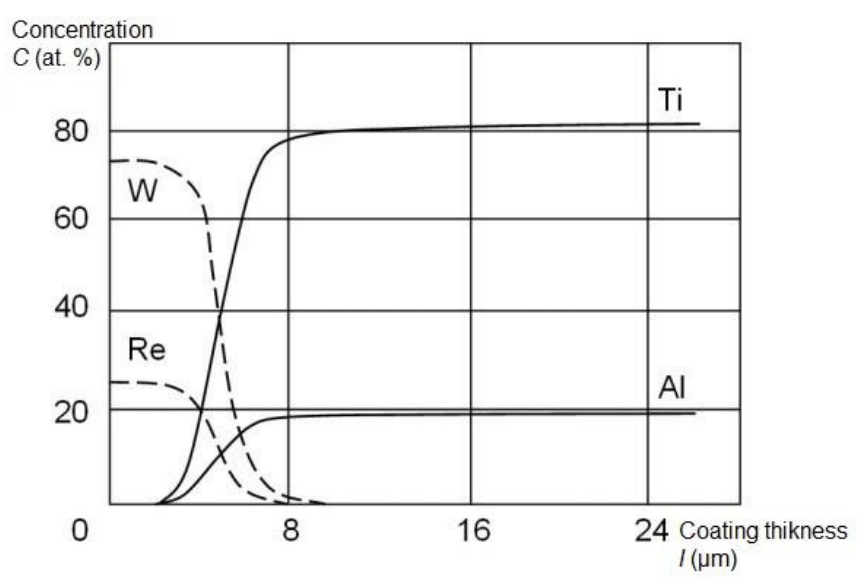

Fig. 5: Distribution of elements over the thickness of the coating obtained by deposition of a $\mathrm{Ti}_{3} \mathrm{Al}$-based alloy from the gas phase onto the $\mathrm{W}-\mathrm{Re}$ wire substrate $\left(T_{\text {sublimator }}=40^{\circ} \mathrm{C}, T_{\text {raw }}=900^{\circ} \mathrm{C}\right.$, and $T_{\text {wire }}=$ $\left.1400^{\circ} \mathrm{C}\right)$.

In addition, we established the fact of a relative decrease in the aluminum concentration in the resulting coatings. Comparing the data on the aluminum concentration in the raw material alloys and the deposited alloys, we can conclude that the transfer rate of aluminum was within the range of $0.5-0.7$ during the process of chemical transport of alloys based on aluminides of titanium.

Fig. 5 shows the concentration distributions of $\mathrm{Ti}$ and $\mathrm{Al}$ over the thickness of the coating obtained from the raw $\mathrm{Ti}_{3} \mathrm{Al}$ alloy on the $\mathrm{W}-\mathrm{Re}$ wire substrate with a diameter of $200 \mu \mathrm{m}$. The resulting coating was characterized by a high uniformity of the composition over its thickness.

\section{CONCLUSION}

Thus, the experimental data have confirmed the validity of the calculations for the gas-phase composition of the titanium-aluminum-iodine system, which indicate the possibility of obtaining titanium-aluminum coatings during the transfer of raw alloys based on $\mathrm{Ti}_{3} \mathrm{Al}$ and $\mathrm{TiAl}$ intermetallic compounds.

The experimental values of the temperatures of dissociation of titanium and aluminum iodides are lower than the calculated ones by $100-200^{\circ} \mathrm{C}$ on average, which can be attributed to errors in the calculation model.

Samples were obtained that had a columnar structure and a high degree of adhesion to the substrate, with a high uniformity of the composition over its thickness. 
The transfer coefficient of aluminum during the chemical transport of alloys based on titanium aluminides lies in the range of $0.5-0.7$, decreasing with an increase in the aluminum content of the raw alloy.

\section{References:}

[1] L. B. Zubkov, "Kosmicheskiy metall: vse o titane" (Space metal: all about titanium), Moscow: Nauka, 1987 (in Russian).

[2] X. Chen, C. Li, X. Bai, H. Liu, S. Xu and Y. $\mathrm{Hu}$, "Microstructure, Microhardness, Fracture Toughness, and Abrasive Wear of In-Situ Synthesized TiC/Ti-Al Composite Coatings by Cold Spraying Combined with Heat Treatment," Coatings 2021, 11(9), 1034; https://doi.org/10.3390/coatings11091034

[3] S.A. Pyachin, T.B. Ershova, A.A. Burkov, N.M. Vlasova, E.A. Kirichenko, M.A. Kulik, V.O. Krutikova. "Preparation and properties of electrospark coatings from Ti3 $\mathrm{Al}$ granules with silicon carbide and boron carbide additives," Lett. Mater., 2019, 9(2) 191-196.

[4] P. Schmidt, M. Binnewies, R. Glaum, and M. Schmidt, "Chemical Vapor Transport Reactions - Methods, Materials, Modeling. Advanced Topics on Crystal Growth," Ch. 9, 2013, pp. 227-305. DOI: $10.5772 / 55547$.

[5] M. Binnewies, M. Schmidt, P. Schmidt "Chemical Vapor Transport Reactions Arguments for Choosing a Suitable Transport Agent," Z. Anorg. Allg. Chem. 2017, 643, 12951311

https://doi.org/10.22226/2410-3535-2019-2-

191-196

[6] F. Hansen, M. Wels, S. Froeschke, A. Popov, D. Wolf, B. Büchner, P. Schmidt, and S. Hampel. "Thermodynamic Evaluation and Chemical Vapor Transport of Few-Layer WTe2," Cryst. Growth Des. 2020, 20, 11, 7341-7349 https://doi.org/10.1021/acs.cgd.0c01004

[7] H. Schâfer, "Chemische Transportreaktionen: Der Transport Anorganischer Stoffe über die Gasphase und seine Anwendungen Verlag Chemie," GmbH Weinheim/Bergstr, Germany, 1964, p. 190 (in German).

[8] R. F. Rolsten, "Iodide Metals and Metal Iodides," Wiley, 1961, p. 441.

[9] A. N. Silenko, S. V. Levin, A. E. Egorovsky, and V. V. Svetikov, "Experimental study of the process of deposition of gas-phase hafnium coatings on long substrates," in "Struktura i svoistva materialov atomnoy tekhniki" (Materials for nuclear technologies), Moscow: MEPhI, 1986, pp. 34-36 (in Russian).

[10] E. S. Bumps, H. D. Kessler, and M. Hansen, "Titanium-aluminum system," in "Titan i ego splavy" (Titanium alloys), Moscow: Inostrannaya Literatura, 1954, pp. 163-174 (in Russian).

[11] https://extxe.com/13923/intermetallidnyesplavy-na-osnove-aljuminidov-titana/ (in Russian).

\section{Contribution of Individual Authors to the Creation of a Scientific Article (Ghostwriting Policy)}

Anna I. Guseva was responsible for the thermodynamic calculations and statistical processing of results.

Arkady N. Silenko has organized and executed the experiments.

\section{Creative Commons Attribution License 4.0} (Attribution 4.0 International, CC BY 4.0) This article is published under the terms of the Creative Commons Attribution License 4.0 https://creativecommons.org/licenses/by/4.0/deed.en US 